\title{
Advantages of immersed tunnels for long water crossings
}

\author{
Evgeny Kurbatcky, ${ }^{1, *}$, and Ekaterina Pestriakova ${ }^{1}$ \\ ${ }^{1}$ Russian University of Transport, 9 b9 Obrazcova Street, 127994, Moscow, Russia
}

\begin{abstract}
In the article there is considered foreign experience of immersed tunnels within transport crossovers construction through continuous river and marine obstacles. There are found out peculiarities, advantages and disadvantages of their construction as analysis result of immersed tunnels already operated worldwide. A large number of transport crossovers built and operated worldwide including the immersed tunnels demonstrate the benefits of such projects in comparison with other types of transport crossovers - bridges and bored tunnels.
\end{abstract}

\section{Introduction}

Immersed tunnels have special advantages for long water crossing since they lie only a short distance below water bed level. As a result, approaches can be relatively short. Compared with high level bridges and dip bored tunnels, the overall length of crossing usually is shorter. The length of the bridge crossing on the flat terrain increases (Figure 1).

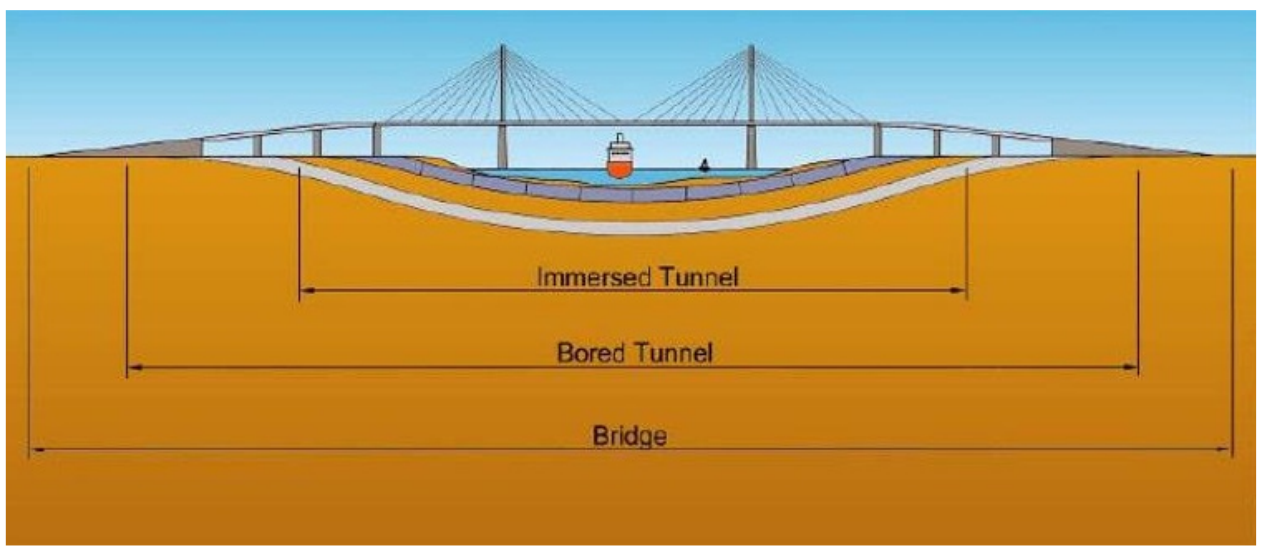

Fig. 1. Compare Length of transport water crossings.

Immersed tunnel can be constructed under any ground conditions. Bedrocks in straits and rivers can be located under lax water-saturated grounds at great depths. Such conditions usually create significant problems in the construction of supports of large-span bridges.

\footnotetext{
* Corresponding author: usd.miit@gmail.com
} 
Currently, more than 100 immersed tunnels have been built and are in operation in the world. They are constructed for different objectives and they have many variations cross sections (Figure 2). Immersed tunnel do not have to be circular in cross section (such as bored tunnels). Almost any cross section can be accommodated, making immersed tunnel particular attractive for wide highways and combined road/rail tunnels. This type of constructions can be used for road tunnels railway tunnels: single-track and double-track, as well as tunnels for simultaneous skipping of railway trains and vehicles.

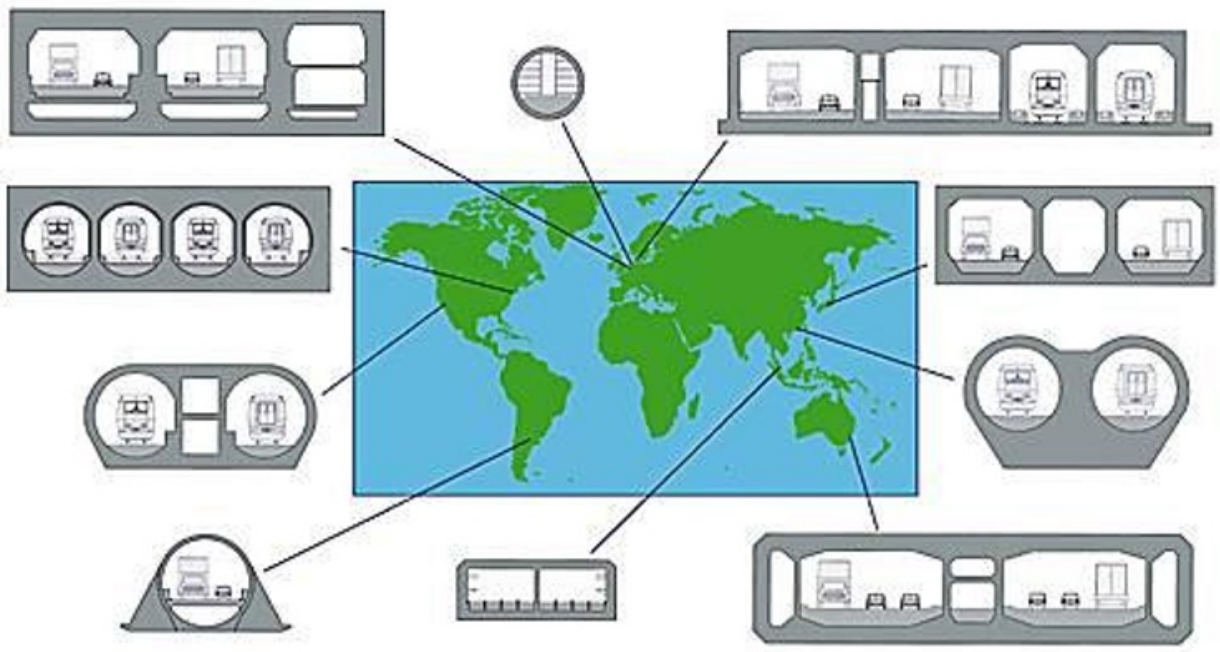

Fig. 2. Types of cross-sections of immersed tunnels and their location.

\section{Tunnel section construction}

Typically, the immersed tunnels are made of reinforced concrete or reinforced concrete sections. Sections are built in docks or in specially excavated floodable basin on the shore (Figure 3).

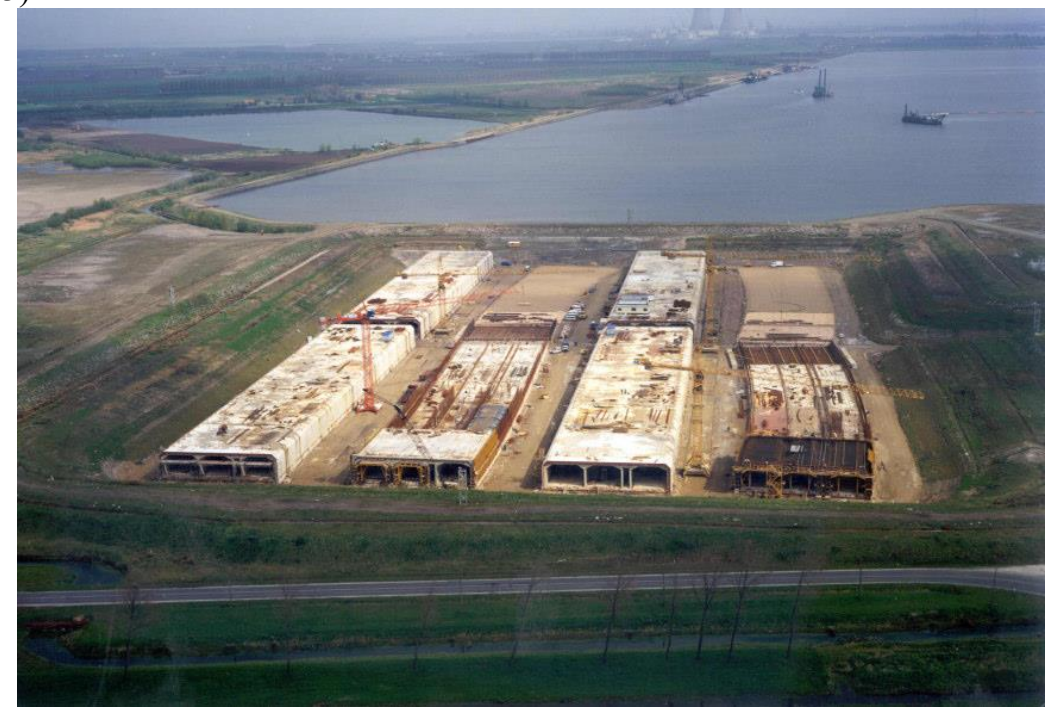

Fig. 3. Tunnel section construction in a special trench (Netherlands). 
In some cases, the place of production of sections can be located at great distances from the place of immersion of sections. As an example, give a view of a reinforced concrete plant located at a distance of $40 \mathrm{~km}$ from the location of the tunnel (Figure 4).

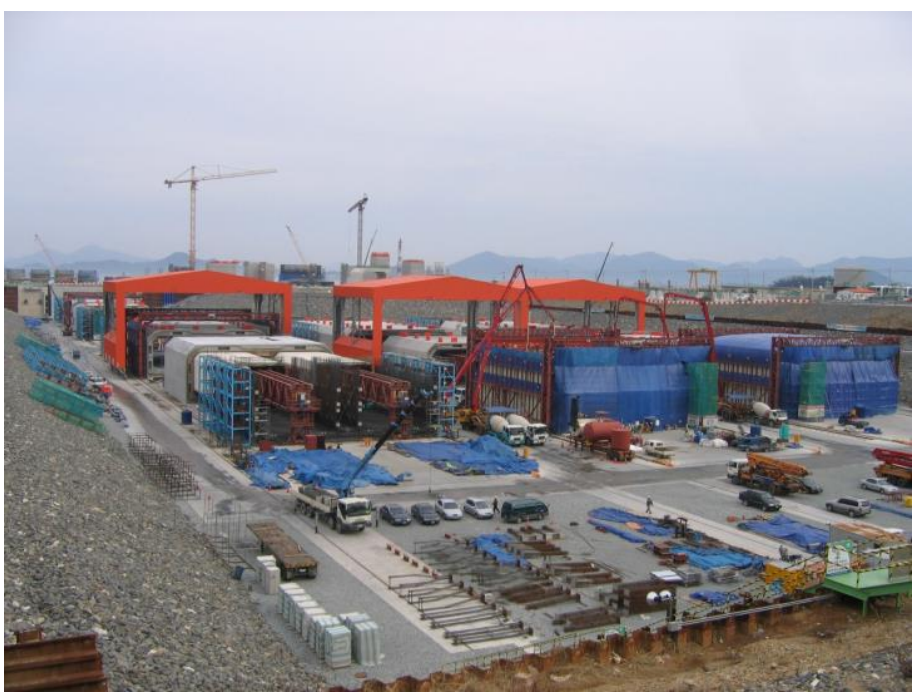

Fig. 4. Type of site for the simultaneous casting of several sections of the tunnel (the western shore of the Gulf of Jinhae).

When the construction of the sections is completed, the basin is filled with water, for which purpose specially installed gates are opened. Before filling the basin with water, temporary bulkheads are applied to the ends of the tunnel elements. Sections are design that they have the necessary buoyancy, so the sections after flooding the trench begin to float (Figure 5).

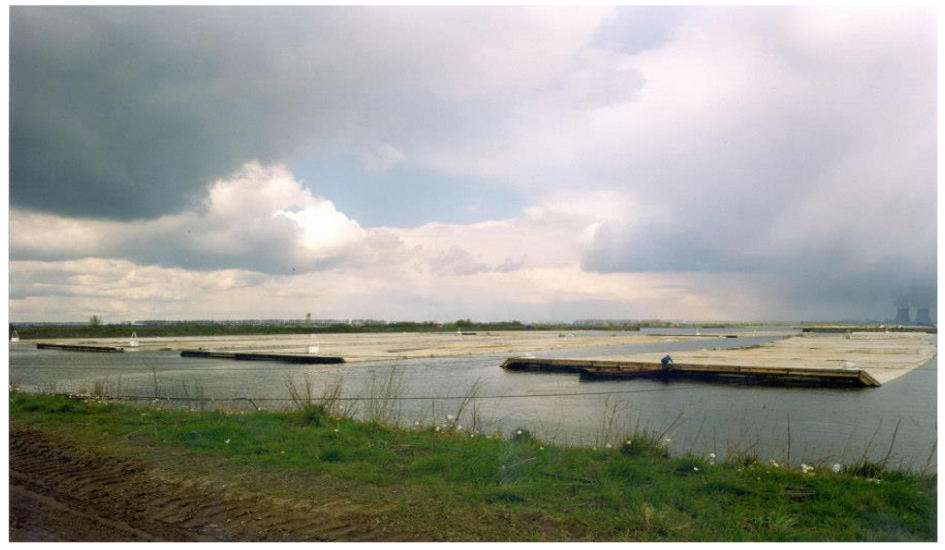

Fig. 5. Tunnel sections prepared for transportation (Netherlands).

\subsection{Transportation of sections to the installation site (immersion)}

The tunnel sections are towed along the water to the installation site.

Immersed tunnel elements are usually floated to the site using their buoyant state (Figure 6). However, sometimes additional external buoyancy tanks attached to the elements would be used if necessary (Figure 7). 


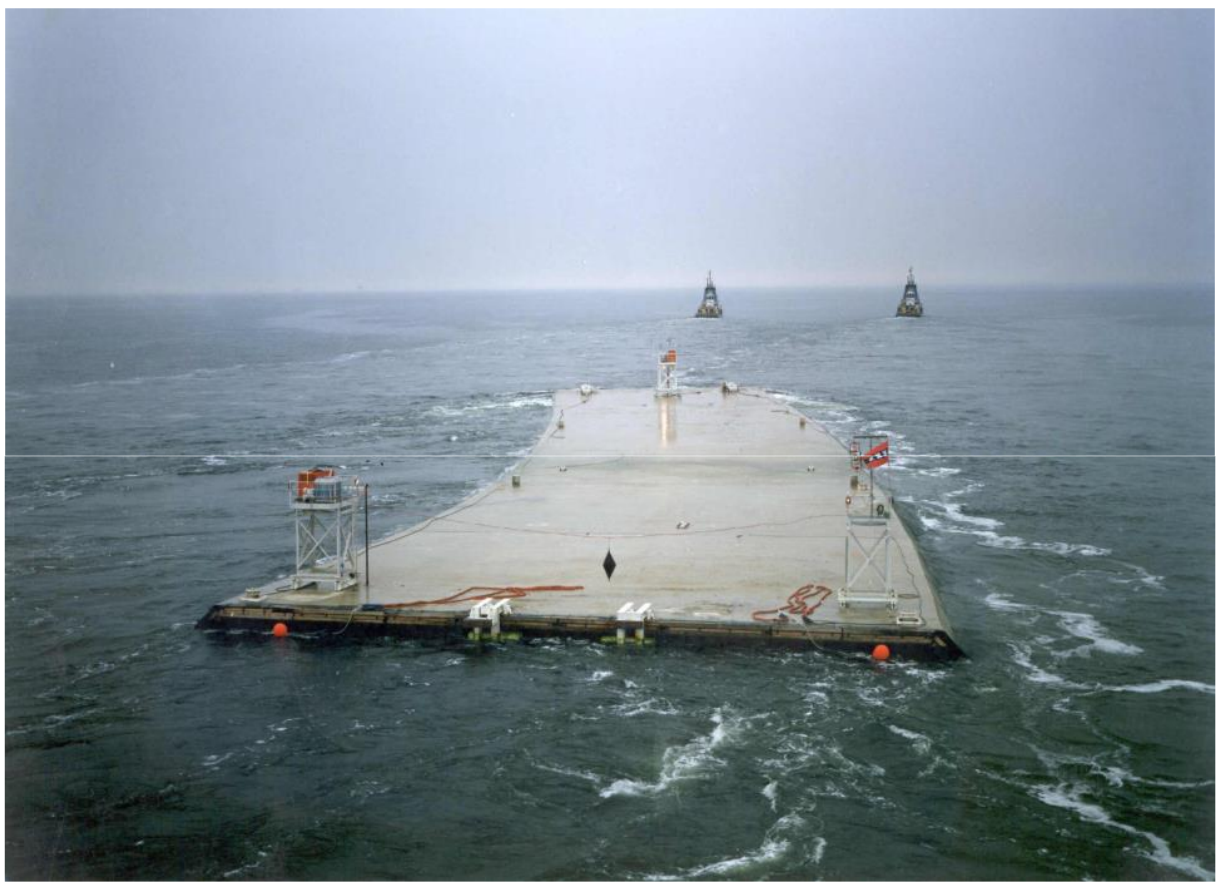

Fig. 6. Transportation of reinforced concrete section to the dive site (Netherlands).

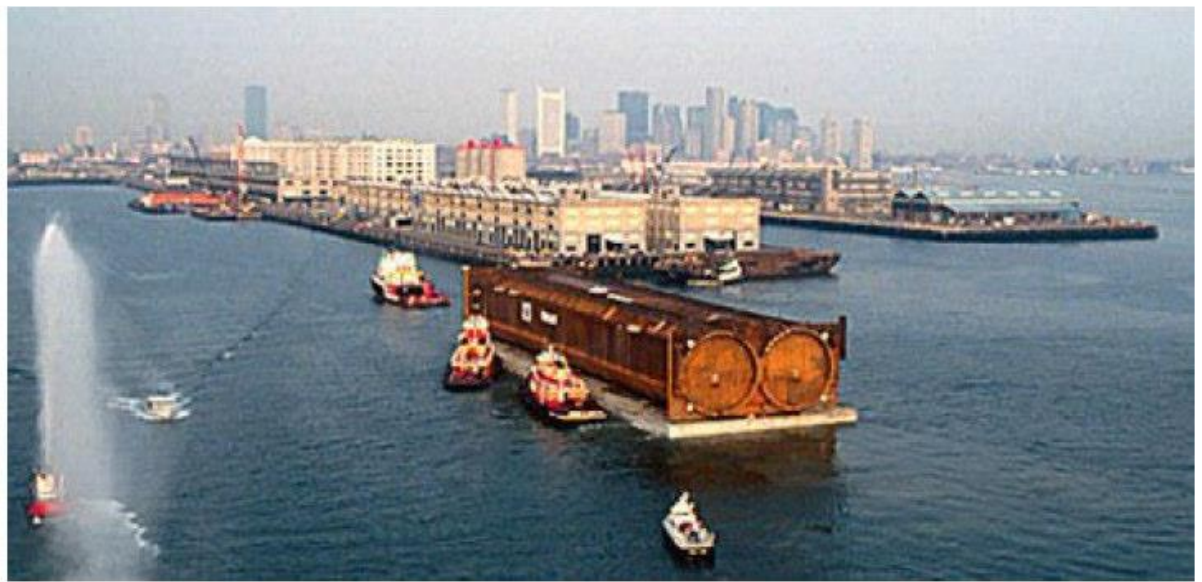

Fig. 7. Transportation of steel sections of the tunnel (Boston).

When constructing a transport crossing through the Bosporus, steel-concrete sections were used, which also had sufficient buoyancy (Figure 8). 


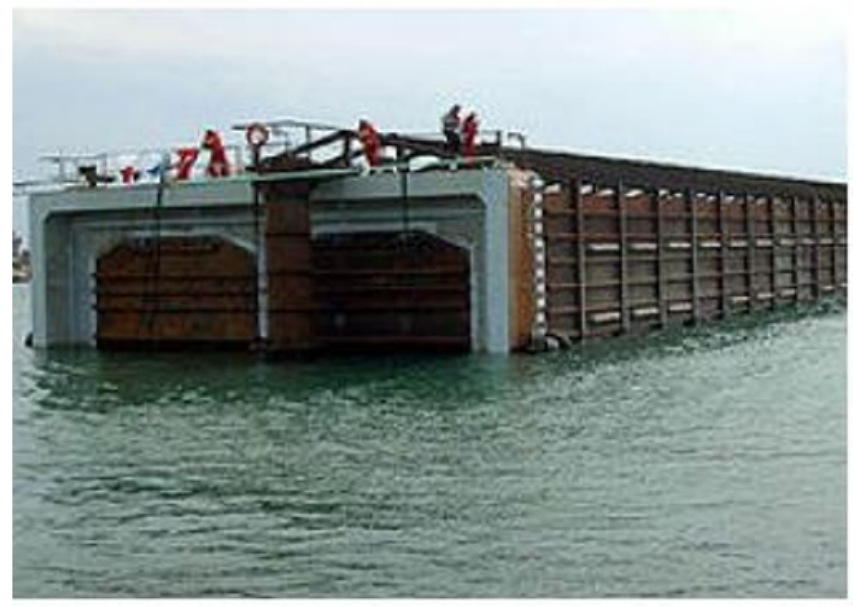

Fig. 8. Transportation of reinforced concrete section.

\section{Preparation of the bases for the installation of sections of tunnels}

The most accepted method preparing trenches for immersed tunnels is the use of grapples and dredges (Figure 9). In areas with high environmental requirements, grapples with sealed buckets are used to reduce water pollution. In the development of hard rock, there may be need for drilling and blasting operations, which is environmentally undesirable.

Works to deepen the bottom, as a rule, are carried out in at least two stages: removal of bulk material; and cuttings of soil. Cutting of the soil should include the removal of at least 1-meter layer of soil after the completion of excavation by a dredger or grab. All alluvial materials: silt, sand, or other materials that can accumulate at the bottom of the trench are removed immediately before the section is lowered.

The trench for the tunnel must correspond to the design plan and the profile of the route, taking into account the possible collapse of the trench walls. Work to deepen the bottom should be carried out in such a way that the width of the bottom of the trench and the profile are preserved when preparing the base and lowering the sections. The bottom of the trench must be filled with soil that meets the design requirements for base materials.
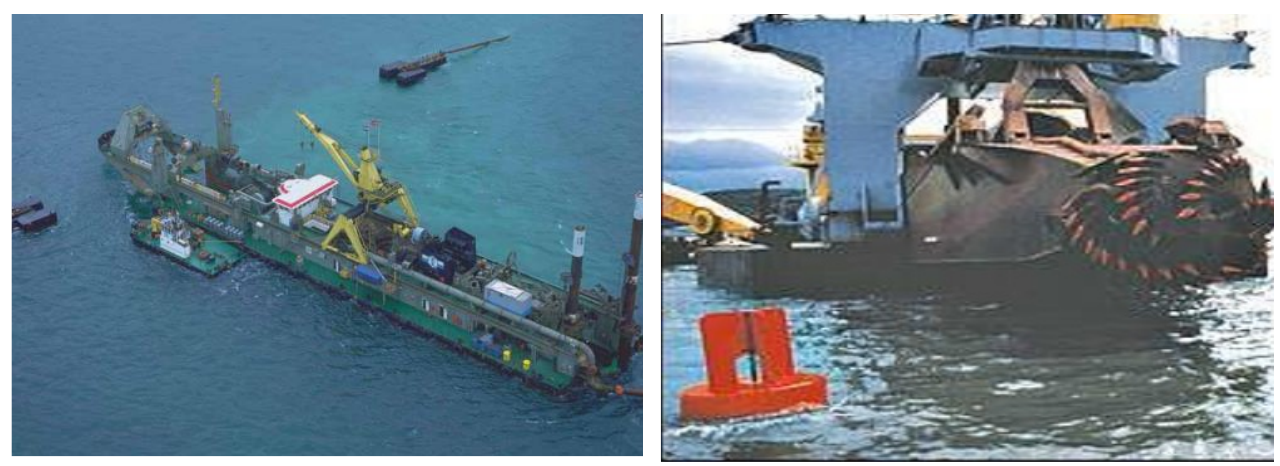

Fig. 9. Multifunctional barge with equipment for deepening and leveling trench and dredger for the development of solid rock. 
To level and form the bottom of the trench, special equipment has been developed for laying the gravel layer. The process is continuous. The equipment is installed on the barge and allows the bottom of the trench to be formed with an accuracy of up to $25 \mathrm{~mm}$ from the calculated mark, which is achieved by the laser system for controlling hydraulic cylinders on the supply pipeline.

\section{Installing the sections in place}

After the sections of the tunnels are delivered to the installation site, the process of immersion into the pre-prepared trenches begins (Figure 10). The immersion process is a rather complicated operation. Usually, the immersed section is lowered some distance from the already installed section and then moves slowly until it comes into contact with the previously installed section. After that, installation wok is carried out to connect the sections.

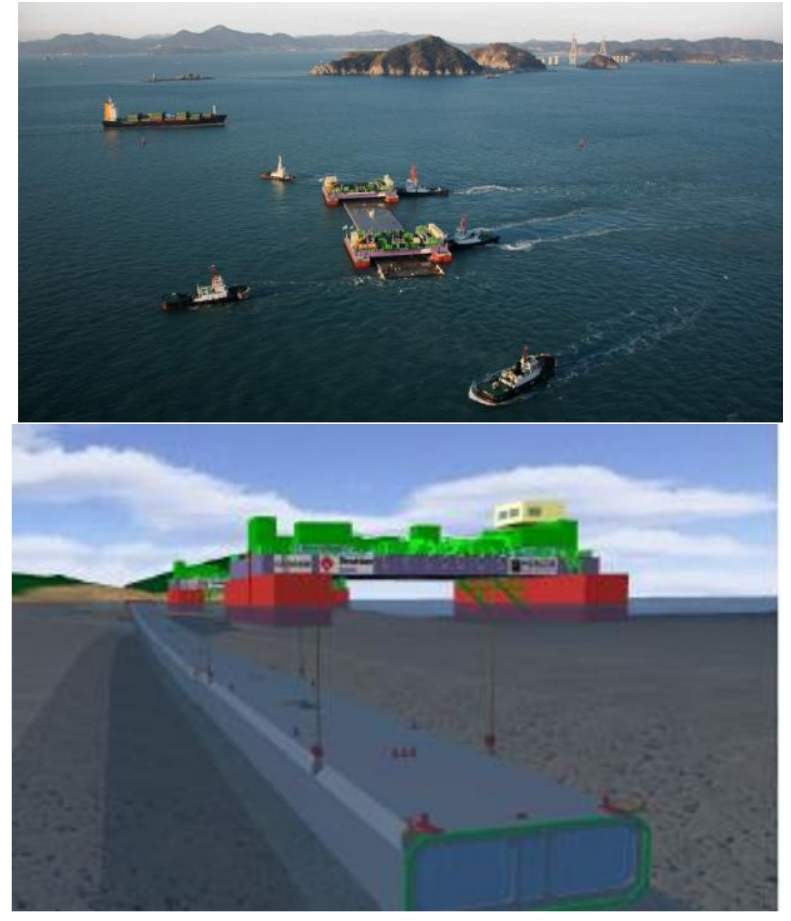

Fig. 10. Submerging sections from a special barge.

\section{Ensuring the from safety of tunnels the impact of wrecks}

To prevent damage to the tunnel lining that happened in ship accidents and from damage caused by anchors, when backfilling is performed, a protective layer of solid ground (Figure 11). The penetration depth of a falling anchor through tunnel roof protection material should be estimated. For this goal a good design method to calculate the anchor penetration depth in granular material is used. The intensity of uniformly distributed loading from a sunken ship should be determined and taking into consideration. 


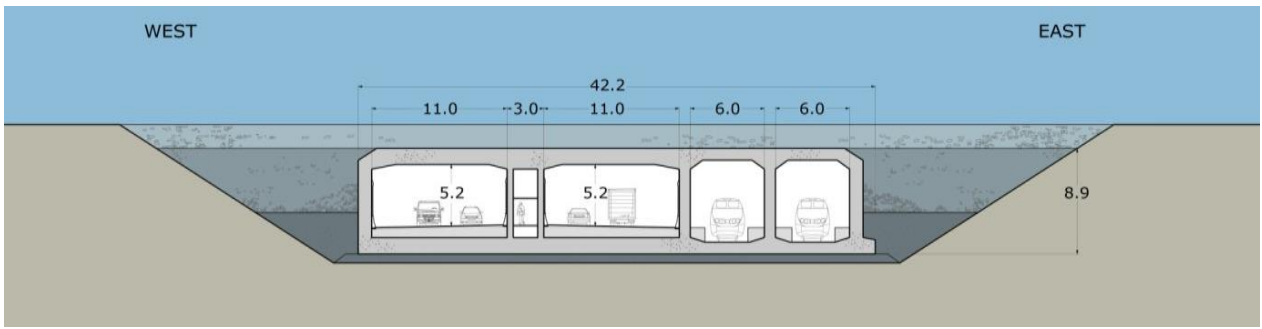

Fig. 11. Example cross section of the tunnel indicating backfill.

In order to ensure tightness and the necessary relative displacement between the sections currently widespread connections with gaskets type «Gina» and "Omega". Figure 12 shows a typical immersion joint.
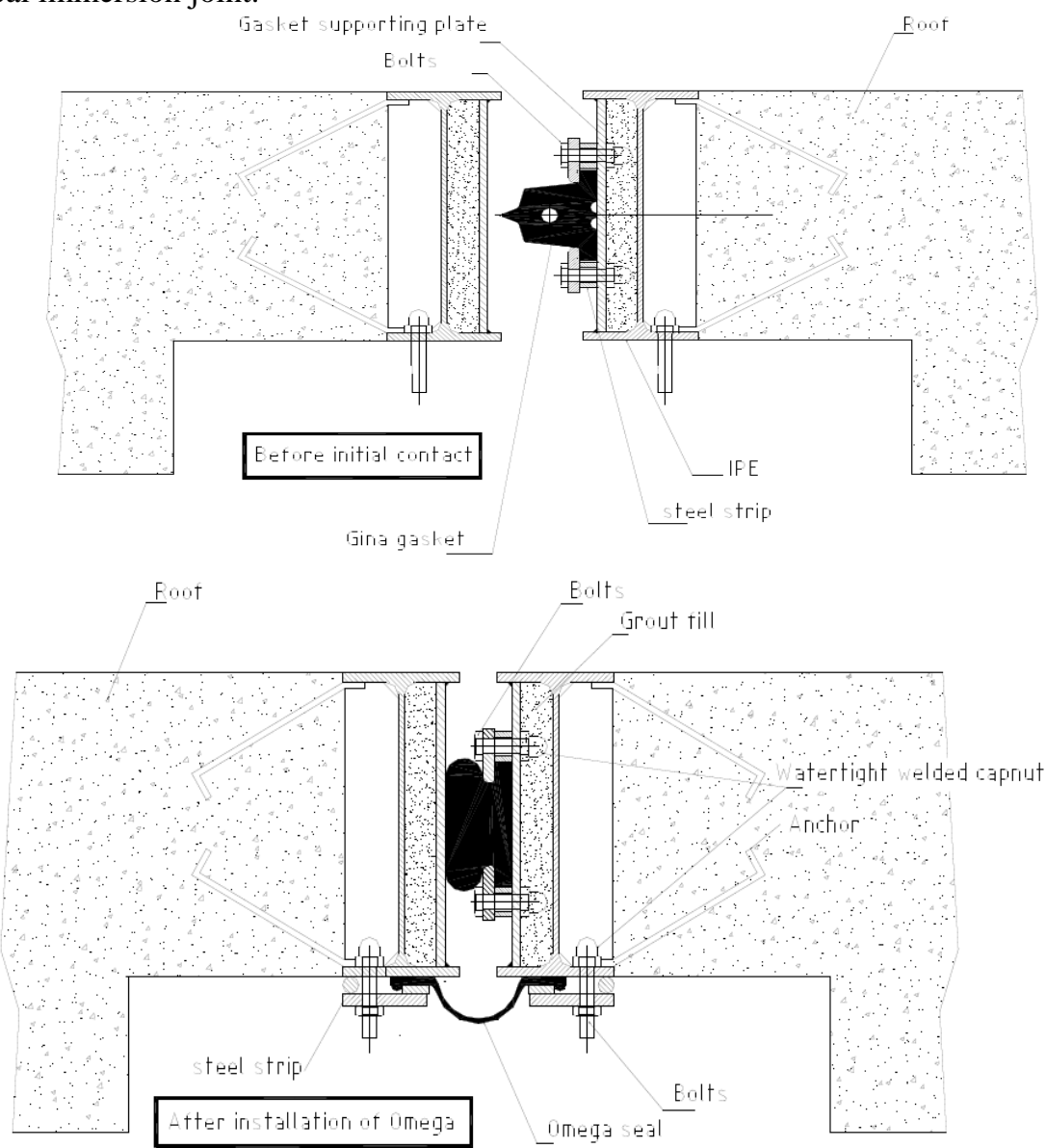

Fig. 12. Connection between sections using "Gina" and "Omega" gaskets.

Connections with such gaskets ensure, without damage, the relative displacements of the ends of the sections of the tunnels that result from precipitation, creep of concrete, temperature changes and, if required, earthquakes. The warranty service life of such compounds is 100 years. 


\section{Advantages and disadvantages of tunnels from lower sections}

A large number of transport transits constructed and operated in the world, including tunnels from immersed sections, indicates the advantages of such projects, in comparison with other types of transport transitions. Let's mention some of them:

1. Simultaneous production of a large number of sections of tunnels on the shore and the simultaneous construction of stages: (construction of sections, preparation of trenches and transportation of sections), allows to significantly accelerate the construction.

2. The construction has no impact on shipping

3. The section of the immersed tunnel should not necessarily be cylindrical (as required for bored tunnel), it is possible to construct tunnels with different shapes of cross sections.

4. Immersed tunnels can be constructed practically for any type of soil, including soft alluvial ones.

5. In the operation of transport crossings the height, the tonnage of vessels passing through straits, gulfs and wide rivers are not limited.

6. The combined transport project, consisting of bridges and tunnels from lower sections, can be more economical than a large bridge project and a bored tunnel.

7. Immersed tunnels can be constructed in areas with increased seismic activity in seismic resistant design.

8. The complex climatic conditions do not affect the operation of the immersed tunnel.

It should be noted that the tunnels from the immersed sections also have disadvantages, which are the effect on the environment: they can influence the habitats of fish, change currents and reduce the transparency of water. But the most important drawback at the moment is the lack of experience in building tunnels of this type in the Russian Federation, as well as the lack of necessary equipment. The general criteria and allowable design method are mainly determined by the national code. There is no such code in the Russian Federation.

Nevertheless, it's time to start using this type of tunnels, especially since in Russia there is a large number of water (sea and river) barriers that need to be crossed by transport transitions, without violating shipping.

\section{Conclusions}

An analysis of constructed and planned transport transitions using immersed tunnels shows that when selecting the intersection of the Nevelskoy Strait by transport routes, the tunnel design from the descending sections can be the most economical, reliable and acceptable from the point of view of costs, construction time and use of modern technologies.

When choosing a version of the bridge to ensure the passage of high-tonnage vessels, it is necessary to build large-span bridges on high supports. Weak water-saturated grounds, deep foundation of bedrock and high seismicity of the area will create serious problems in the construction and operation of such structures.

The natural vibration frequencies of the large-span bridges fall into the region of the dominant frequencies of earthquakes, which can lead to resonance phenomena and damage the structure even under weak seismic influences. Note that in the vicinity of the Nevelsky Strait earthquakes of magnitude 9 on the MSK-64 scale are possible.

Tunnels are less susceptible to seismic impacts, since in them, unlike ground structures, there are no resonant phenomena. When seismic waves pass, the tunnels are deformed in the same way as the surrounding soil massif, if the soil is solid, or much less if the soil is weak. These deformations are usually small and do not pose a serious danger for tunnel lining. 


\section{Reference}

1. J.C.W.M. De Wit, E. Van Putten, Immersed Tunnels: Competitive tunnel technique for long (sea) crossings

2. Technical Manual for Design and Construction of Road Tunnels Civil Elements (U.S. Department of Transportation Federal Highway Administration) 